\title{
Cell Therapy in Parkinson's Disease
}

\author{
Rafieh Alizadeh ${ }^{1}$, Soraya Mehrabi ${ }^{2}$, Mahmoudreza Hadjighassem ${ }^{2,3,{ }^{*}}$ \\ ${ }^{1}$ Department of Anatomy, Tehran University of Medical Sciences, Tehran, IR Iran \\ 2 Department of Neuroscience, School of Advanced Medical Technologies, Tehran University of Medical Sciences, Tehran, IR Iran \\ 3 Brain and Spinal cord Injury Research Center, Tehran University of Medical Sciences, Tehran, IR Iran \\ ${ }^{*}$ Corresponding author: Mahmoudreza Hadjighassem, Department of Neuroscience, School of Advanced Medical Technologies, Tehran University of Medical Sciences, 88 Italia St. \\ Ghods St., Keshavarz Blvd., 1417755469 Tehran, IR Iran. Tel.: +98-2188991111, Fax:+98-2188991117, E-mail: mhadjighassem@tums.ac.ir. \\ Received: February 9, 2013; Revised: June 8, 2013; Accepted: September 30, 2013
}

\begin{abstract}
Context: Parkinson's disease (PD) is one of the common neurodegenerative disorders, characterized by the gradual loss of dopamine (DA) containing neurons in the substantia nigra. It is currently treated by L-DOPA and DAergic drugs. Although these treatments are very effective in the beginning of the disease, but they are not curative and have side effects in chronic use.

Evidence Acquisitions: The aim of cell replacement therapies for PD is looking for a long-lasting relief of patients' symptoms. Different sources of stem cells are recruited to establish a long lasting treatment for PD. We have categorized them into embryonic stem cells from the fertilized egg, neural stem cells from the embryonic or adult brain, mesenchymal stem cell, and stem cells from other tissues. In this review we used three key words "Parkinson's disease, stem cells and neostriatum transplantation" to search in "PubMed" search engine. We found more than hundreds of publications but limitation for citation led us to select only those that were more innovative.

Results: Cell replacement therapies in PD aim to provide greater long-lasting relief of patients' symptoms. Although the transplants survive, reinnervate the striatum, and generate adequate symptomatic relief in some patients yet side effects are still major concern. Conclusions: This article reviewed different sources of cell used in transplantation and focused on their advantages and disadvantages in transplantation studies.
\end{abstract}

Keywords: Parkinson Disease; Stem Cells; Neostriatum; Transplantation; Dopaminergic Neurons

\section{Context}

Parkinson's disease (PD) is a common neurodegenerative disorder presented by motor symptoms such as bradykinesia, rigidity and tremor. Gradual loss of nigrostriatal dopamine (DA) neurons and neuronal degeneration in non-DAergic systems is the hallmark of PD (1). Current therapies have focused on medical and surgical treatment for controlling these symptoms. Levodopa, DA agonists, and monoamine oxidase-B inhibitors are effective pharmacological therapies in the early stages of the disease. Levodopa is still the most effective drug, but the side effects of long term usage of this drug such as dyskinesias and failure to change the nonmotor symptoms like psychiatric and cognitive deficit led research to find more effective therapies (2). New therapies during the past couple of decades have improved treatment of PD such as Deep Brain Stimulation (DBS) of subthalamic neuclei and neural replacement therapy using stem cells (3).

\section{Evidence Acquisition}

New therapies should ideally be able to relieve patients from all kinds of symptoms. DA producing cells implantation to injured site may replace or rescue functional neurons and restore physiological neural circuits (4). Hypothetically, DA neurons could be made from stem cells of four different sources: 1) Embryonic stem cells (ESCs) from the fertilized egg, 2) Neural stem cells (NSCs) from the embryonic or adult brain, 3) Mesenchymal stem cells (MSCs), 4) Stem cells from other tissues. Non-NSCs need to differentiate to NSCs before use for transplantation. Both MSC and NSC are related to somatic stem cells and can develop to neuronal cells. NSCs isolated from embryonic or adult brains have less propagation capability than ESCs. MSCs derived from umbilical cord and bone marrow have the ability to differentiate to multiple lineage of neural cells and have a good expansion capacity (5). In this article, we present 
an overview of different stem cells that may be used as an origin of donor tissue for cell replacement therapy in PD.

\subsection{Embryonic Stem Cells}

ESCs are obtained from the blastocyst, with the ability of self-renewal and differentiation into several types of cells including DAergic neurons (6). Isolation of ESC line was done in 1981 from mouse blastocyst and human ES cell lines were generated 17 years later (7-9). In order to show the effect of stem cells therapy on PD, an animal model was recruited. For making an animal PD model, neurotoxic compounds such as (1-methyl4-phenyl-1,2,3,6-tetrahydropyridine) MPTP and 6-hydroxydopamine (6-OHDA) were recruited, although the extent to which they lead to mimic true PD symptoms still remains unclear (4). They are pluripotent cells with the ability to differentiate to different type of cells including DAergic neurons (10). Survival of transplanted rodent and human ESC-derived DAergic neurons into the striatum of PD rat was studied, and it showed some degrees of recovery $(11,12)$. However, follow-up studies failed to show long term survival of ESC-derived DAergic neurons in recipients $(11,13)$. ESCs can be differentiated into neural progenitor cells (NPC), but functionality is required to become a DAergic neuron. Studies showed cocultured ESC with feeder cells that contain stromal cell-derived inducing activity (SDIA) enhanced neuronal percentage in culture (14). High percentage of primate ESCs when cocultured with mouse Sertoli cells differentiated to tyrosine hydroxylase $(\mathrm{TH})$ positive after three weeks of induction. These cells were alive in murine models for two months (15). McKay and colleagues showed that the presence of fibroblast growth factor 2 (FGF-2) facilitates in vitro generation of DA neurons in high yield from mouse ESCs (16). This application was also used to generate DA neurons for non-human primate ESC (17). It has been recently reported that overexpression of Nurr-1, DAergic specific transcription factor, in ESCs forced them to induce DAergic neurons. In vivo study of these cells by injecting into striatum of rat PD model revealed that they could survive, extend processes and reduce deficits (11). Morizane cultured mouse embryonic stem cells in the presence of various cell lines and noticed that bone marrow-derived stromal cell line was a potent inducer of neuronal differentiation (18). These cells produced DA and showed substantial short-term survival (at two weeks) after transplantation to the mouse striatum. Furthermore, studies revealed that incubation of primate ESCs with the stromal cell-derived was able to generate neurons expressing mesencephalic DA markers (19). These transplanted cells functioned as DAergic neurons and de- creased MPTP induced PD symptoms in primate models (17). DAergic cells can be obtained from several human ESC lines and show DAergic characters after transplantation (20). After isolation of human ESCs in 1998, public interest increased in ESC therapy (21). Three types of central nervous system cells including astrocytes, neurons, and oligodendrocytes could be produced and isolated under specific conditions from human ESCs (22). Neural progenitor cells (NPC) can be obtained from the differentiation of human ESC. Reubinoff and colleagues by culturing human ESC on a feeder cell layer and supplementation of medium with basic fibroblast growth factor (bFGF) and epidermal growth factor (EGF) differentiated the human ESC to NPC (23). Human ESCs in the presence of signaling protein sonic hedgehog (shh) and FGF-8 with telomerase-immortalized human fetal midbrain astrocytes potentiate DAergic neurons. The grafted cells (in striatum) yield a significant, substantial, and long-lasting restoration of motor function in animal PD model (12). Efficiency of neuronal differentiation from human ESC was increased in the presence of $50 \%$ conditioned medium from human hepatocarcinoma cell line, HepG2 (24). However, after transplantation, cells survived but less than $2 \%$ expressed DAergic markers (23). So far, human ESCs have not been shown to produce a pure specific population of cells after differentiation (8). DAergic neurons derived from human ESC were transplanted into the striatum of MPTP induced Parkinsonian monkeys, after 14 weeks showed fluorodopa uptake detected by a positron emission tomography (PET) study and had improvements in their motor deficit (25). Studies revealed that differentiation of human ESC prior to transplantation reduced teratoma formation (26). This side effect can be reduced or ceased if differentiated NPC from human ESC is used. Cell sorting techniques such as GFP-dependent sorting, because of their low ability of differentiation and proliferation (27) and antibiotic selection (28), as well as immune selection procedures facilitate isolation of NPC from culture (29). Symptomatic relief after at least eight weeks of human ESC derived DAergic neurons transplantation was seen (4). Although ESCs are one of the most useful cell sources for transplantation, yet a major concern is tumor and cancer formation. Genomic alterations with longer passage turned the cultured human ESC to cancerous cells. Reports showed that cell sorting or prolonged differentiation may reduce the risk of tumor formation $(26,30,31)$. In summary, human ESC is a promising source of NPC and DAergic neurons. Neurons derived from it could survive, extend their processes and express DA which ameliorates the induced deficit in animal models. However, the risk of tumor and cancer formation from using human ESC is still a major concern (4). 


\subsection{Neural Stem Cells}

NSCs are multipotent cells, with self-renewal ability and give rise to neuronal lineage such as neurons, oligodendrocytes, and astrocytes. During the developmental stage, primarily, progenitor cells appear in the telencephalic ventricle. Cells lie in this zone, grow exponentially by symmetrical cell division followed by asymmetric cell division and this gives rise to another precursor cell and neuron. In the next step, the generated precursor cell migrates from the ventricle to form the cortical plate (32). Recent studies have identified NSCs in the adult brain, besides the developing brain (33).

\subsubsection{Embryonic or Fetal Neural Stem Cells}

Fetal NPC have been isolated from different species such as primates, porcine and murine fetal ventral mesencephalon. Studer and colleagues in 1998 showed that in the presence of mitogens such as FGF-2, in the medium, increased expansion of ventral mesencephalic (VM) cells was obtained from E12 rats (34). This group, by removal of FGF-2 from medium culture of rat's embryo mesencephalic tissue, induced them to form THpositive neurons. Although these cells look like DAergic neurons, their survival rate was not promising after transplantation (35). It has been shown that Fetal brain neural SC derived DAergic neurons are associated with lower risk of tumor formation and immune rejection compared to ESCs (36). On the other hand, neural progenitors can grow as primary culture in appropriate media (8). Two culture protocols used for growing NSCs: 1) brain tissue cultured in the medium containing mitogens EGF and/or FGF-2, generating free-floating colonies and 2) adherent immortalized NSC cell lines. It has been shown that NSCs can integrate into a neural network, restore the projection of substantia nigra to striatum, reduce symptoms, and it has been reported that they can be detectable in the host environment after five months of transplantation (37). Studies have shown that FGF-2 enhanced the differentiation of NSCs into DAergic neurons by approximately $80 \%$ (38). Nurr1 is a transcription factor and its over-expression in the ESCs or NSCs facilitates differentiation to DAergic neurons (11). McKay has reported that the presence of ascorbic acid in the medium of cultured mesencephalic precursors promotes DAergic differentiation (35). Moreover, if environmental oxygen remains low; the induction of DAergic neurons in the presence of ascorbic acid will be enhanced (39). Another group tested the EGF effect on rat embryo's mesencephalic culture (40). They expanded neurospheres and showed that in the presence of soluble cytokines, glial cell line-derived neurotrophic factor (GDNF), striatal conditioned medium, and insoluble (mesencephalic membrane fragments) molecules, they can subsequently be differentiated into a DAergic neurons (41). Presence of bFGF in the serum-free medium and use of pre-coated culture dishes enhanced cell population by ten folds. Free-floating aggregations of the cells in a bFGF free medium containing 10\% fetal bovine serum differentiate the cells and increase DAergic neurons by up to $18 \%$. Transplantation of these cells into rat models of PD ameliorates distortion of rotator behavior in these animals. In 1979 Perlow and colleagues showed allotransplanted fetal ventral mesencephalic (VM) tissue into a rat model of PD survived and exerted some functional recovery (42). Lesionized 6-OHDA rat transplanted with a solid piece of embryonic rat VM into the neostriatum showed DAergic fiber outgrowth from the graft into the host striatum,, improving the amphetamine-induced rotation test, but not recovering thecontralateral neglection (43). It might be due to the lack of proper innervations of graft into the brain lesion, thus DA-rich nigral cell suspension method for transplantation was developed (44). Previous studies reported that nondifferentiated NSCs taken from a human source have limited differentiation in vivo and only partially affect PD-like symptoms (45). A small number of NSC progeny can differentiate into DA phenotypes (1). A recent study showed that nondifferentiated NSCs implanted into PD primates survived, migrated, and had a functional impact (46). Transplantation of human fetal mesencephalic tissue obtained from six to nine weeks aborted fetus to the striatum reverses behavioral deficits in PD animal models through restoration of striatal DA transmission (47). Human mesencephalic precursor cells were cultured in vitro, in the presence of EGF and FGF-2 in a low oxygen atmosphere. Cultured cells were differentiated in media containing interleukin 1 beta (IL$1 \beta$ ), interleukin 11 (IL-11), leukemia inhibitory factor (LIF) and GDNF. Up to $1 \%$ of the precursor cells showed THphenotype (41). Restoration of nigrostriatal pathway in PD animal model by dissociated VM tissue from human embryos was also studied to find whether transplanted cells could integrate into the nigrosterial pathway (48). After 13 - 20 weeks, transplanted VM neurons became THpositive with terminal connection to striatum. Based on previous studies, the first clinical trials were done in 1980s. Allotransplantation of fetal VM tissue in PD patients resulted in improvement of some symptoms (4). Human embryonic VM grafted to striatum of PD patients, who do not respond to the replacement therapy, show symptom reduction with functionality improvement (49). However, the clinical improvement was very variable from one patient to another. The first problem was the appearance of disabling dyskinesia in some patients (50). Secondly, if it becomes a routine source of transplantation, a large number of fetuses are required per patient, while there are ethical implications regard- 
ing the use of aborted tissue (4). Since the initiation of first graft in 1987 more than 200 patients with PD have received intra-striatal grafts of human embryonic mesencephalic tissue. Clinical evaluation demonstrates that grafted DA neurons can survive in re-innervate part of the host striatum. The majority of patients with surviving grafts showed long-term improvement of therapeutic value, but complete symptomatic relief was not seen (51). Using PET showed increased uptake of flourodopa in grafted primary mesencephalic DA neurons (52) and histopathological studies revealed neuritis extension in grafted neurons up to $7 \mathrm{~mm}$ with synaptic formation (53). Follow-up studies did not report any immunological rejection of the grafts, even several years after withdrawal of immunosuppressive drugs (54).

\subsubsection{Adult Neural Stem Cells}

Endogenous adult NSCs were identified by Altman and Das (55) in 1965 who discovered signs of mitosis in the rat hippocampus. Until 1992 when Reynolds and Weiss isolated multi-potent cells from adult striatum no progression was seen in this field (56). Since then, many groups isolated and cultured obtained cells from various brain regions such as cortex, optic nerve, retina, hippocampal dentate gyrus (DG), hypothalamus, septum, spinal cord and substantia nigra in vitro. Further studies revealed in vivo neurogenesis in the sub-ventricular zone (SVZ), olfactory bulb, and the sub-granular zone (SGZ) of the DG. the other studies revealed existence of stem cell population with proliferative capabilities in the adult brain, opening up therapeutic potential for neurodegenerative disease (4). Using adult mouse SVZ obtained cells, Daadi and Weiss produced a small number of TH-expressing cells by culturing them in the presence of FGF-2 and glial cell in conditioned media (57). Lie and colleagues have shown the existence of progenitor cells in adult substantia nigra, which only give rise to glial cells in situ and not to neurons. However, when grafted in the hippocampus, appropriate signals induced neuronal like cells. The major challenge will be to identify those signals which can drive the substantia nigra cells down to DAergic neuronal lineage (58). The major advantage of adult NSCs could be the lack of immune reaction. However, several problems with this approach might be predicted; obtaining these cells from SVZ of human is very difficult. Moreover, whether these human cells can expand in sufficient numbers to DA neurons should be studied. Indeed, in a PD patient these cells may be functionally impaired due to age, disease process or long-term drug treatment (54).

\subsection{Mesenchymal Stem Cell}

MSCs are found in the bone marrow and umbilical cord. In 2004, in a study highly specific induction of DAergic neurons was demonstrated from both rat and human MSCs by Dezawa and colleagues (59).

\subsubsection{Bone Marrow}

Bone marrow-derived stromal cells and mesenchymal SCs (MSCs) have been considered as potential sources for transplantation in PD (1). Bone marrow contains hematopoietic and MSCs (5). After injection of bone marrow-derived stromal cells into the striatum of a mouse PD model, low population of TH positive cells was observed (60). However characteristics of DAergic neurons, DA production, in this study were not assessed. Jiang recently described a protocol for induction of DAergic neurons from MSCs. Induction of expressing DAergic neuron markers (DA decarboxylase- and TH-immunoreactivity) after culture of MSC in the presence of FGF-2, FGF- 8, and BDNF was shown (61). The best route of injection would be systemic injection. However, in the experiments of Jiang and colleagues, the intravenous infusion of the MSCs did not give rise to any engraftment in the brain (61). Intrastriatal injection of mouse MSCs exhibits significant improvements in the rotarod test compared to systemic injection, and the cells survive for more than four months (60). Moreover, TH gene was transfected into MSC and injected into striatum of a PD rat. The grafted TH-engineered rat MSCs showed TH gene expression efficiency of about $75 \%$ and reduction in the rounds of asymmetric rotation (62). Unlike other stem cells, MSCs are capable of migrating to lesion sites to repair diseased cells and tissues (63). Therefore MSCs are safe and ethically acceptable sources of stem cells moreover they can be obtained from the patient's own bone marrow (5). Recently, a clinical trial on advanced PD patients with unilateral transplantation of autologous bone marrow-derived MSCs into the sublateral ventricular zone reported modest clinical improvement with no adverse effects such as tumor formation at 12 months (64). Survival of transplanted cells was not assessed by PET in this study (47). Although promising data were generated from MSC transplantation, yet more studies are needed to elucidate survival of transplanted cells and identify DAergic properties of injected cells and integration of cells into neuronal network. In summary, easy accessibility of MSC compared to other mentioned sources bring more attention to the use of these cells in replacement therapy for PD. Researchers used these cells as a shuttle to deliver TH gene, or directly injected them into striatum. Although some benefits after transplantation of MSc has been shown in rodent models, the major issue is differentiation of MSCs to neurons and how much they can integrate in to the neuronal network and properly secrete DA.

\subsubsection{Umbilical Cord}

Umbilical cord cells (UCCs) are another potential source of pluripotent cells. After differentiation, the cord bloodobtained precursor cells give rise to a relatively high proportion of oligodendrocytes ( $11 \%$ of the total popula- 
tion of differentiating cells). Easy accessibility and long term preservation make UCCs a new promising source of neuronal precursors. It has been shown that coculturing with primary cortex enhances neuronal differentiation through paracrine trophic effects of neuronal cortex (8). Another MSC source, which can be obtained from the human umbilical cord Wharton's Jelly, is the umbilical cord matrix stem cell (UCMS). Human UCCs were depleted from hematopoetic cells and their neuronal lineage was expanded in the presence of thrombopoietin, flt-3 ligand, and c-kit ligand (TPOFLK); however, results from in vivo use of these cells are not available (65). Transplantation of undifferentiated human UCMS cells into the brains of nonimmune suppressed PD rats' ameliorated apomorphine, induced rotations in the pilot test (66). The advantages of UCMs over MSCs are low cost, pain-free collection, and continuation of surface markers expression after freeze-thaw processing. Taken together, evidence showed that MSCs could be a useful source of autologous stem cells for cell replacement therapy in PD, but still they need to differentiate to neuronal expressing cells under certain conditions, which change the functional rate of these kinds of cells when transplanted into parkinsonian human brain.

\subsection{Other Cells}

\subsubsection{Fibroblast Cells}

Another promising source of stem cells (SCs) is adult fibroblasts that are reprogrammed to so-called induced pluripotent SCs (iPSCs) (67) and then differentiated to DAergic neurons. The iPSC technology increased the possibility of generating a new source of patient-specific DAergic neurons, which could theoretically also be used for autologous transplantation $(68,69)$. It has been shown that over expressing four transcription factors Oct4, Sox2, Klf4, and c-Myc induces pluripotency in mice fibroblasts. DAergic neurons were first generated from mouse iPSCs, transplanted into the striatum of a rat model of PD and shown to ameliorate functional deficits (69). Such neurons survived after transplantation into striatum of PD rodent and produced some degree of functional recovery (70). Recently, human derived fibroblast was induced to DAergic neurons (71) and injected into PD patients (70). These cells can be obtained from the patient themselves, minimizing the immune reactions. Such neurons survived transplantation into the striatum of PD rodents and produced some degree of functional recovery (70). Wernig and colleagues (69) and Hargus et al. (70) minimized the risk of tumor formation by separating contaminating pluripotent cells and committed neural cells using fluorescence activated cell sorting (FACS). Indeed, Hargus and colleagues reported only a few graft-derived axons re-innervating the rat striatum, which is clearly less than those of human fetal mesencephalic tissue transplants, improving only asymmetrical rotation in rat model with no effect on other phenotypes (70).

\subsubsection{Sympathetic Ganglion Neurons}

Research on sympathetic ganglion neurons as donor tissues has been reported for over almost two decades. As both adrenalin and DA belong to the monoamine proteins family, researchers by transplantation of adrenergic tissue, obtained from cervical or thoracic sympathetic trunk, into the striatum of patients reported some kinds of benefit (72).

\subsubsection{Adrenal Medulla}

Madrazo et al. in 1987 pioneered using of adrenal medullary tissue as a source of DAergic neurons (73). However, little benefit was obtained from medulla transplantation (74).

\subsubsection{Carotid Body}

The carotid body found near the bifurcation of the common carotid artery, is a chemosensory organ which cells release DA in response to hypoxia (75). These cells have the potential of dividing in response to a hypoxic environment and have been reported to better transplantation survival rate compared to nigral stem cells (76). Studies showed that the intra-striatal transplantation of carotid body cells reduce motor deficit in parkinsonian rats (76) and MPTP-treated monkeys (77). Preliminary auto-graft transplantation results indicate that these kinds of cells may be a viable clinical approach, but side effects such as autonomic feature of PD patient and extent of symptoms reduction must be considered (4).

\section{Results}

Although using stem cells as a new source of therapy brings hope for the research field, but there are many issues, which should be resolved before testing in PD patients such as scientific, clinical and ethical problems. All above-mentioned stem cells have their own advantages and disadvantages when considered for cell replacement therapy in PD. For example, ESCs with highest proliferation and differentiation rates have teratoma formation capacity which is a real safety risk. On the other hand, embryonic neural progenitor cells show good neuronal differentiation potential but ethical and immune responses are of concern. NSCs and MSCs taken from the patients themselves might increase safety of transplantation but survival and long-time benefit should be studied further. IPSC is a new line of cell which may be derived 
from the patient itself and reprogrammed to induce to DA neurons.

\section{Conclusions}

Most of the cells discussed in this review need to be differentiated or reprogrammed to induce DA neurons under certain conditions. A major question is whether this condition is provided in the human body for these kinds of cells, and to what extent they can act as DA neurons. Research in the stem cell field in the future should focus on obtaining NSCs with endogenously capability of production of DA such as olfactory DAergic cells in order to not only ameliorate the symptoms of PD but also lessen ethical, safety and manipulation processing.

\section{Acknowledgements}

The authors greatly acknowledge Dr. Abbas NorouziJavidan for his help.

\section{Authors' contribution}

Literatures search: Rafieh Alizadeh and Sorraya Mehrabi; Supervision, Writting and Editing: Mahmoudreza Hadjighassem.

\section{Financial Disclosure}

Authors have no financial interests related to the manuscript material.

\section{Funding/Support}

This project is supported by grant 90000255 , Iran National Science Foundation; grant 19933, Brain and Spinal Cord Injury Research Center.

\section{References}

1. Politis M, Lindvall O. Clinical application of stem cell therapy in Parkinson's disease. BMC Med. 2012;10:1.

2. Isacson O. Problems and solutions for circuits and synapses in Parkinson's disease. Neuron. 2004;43(2):165-8.

3. Lindvall O, Bjorklund A. Cell therapy in Parkinson's disease. NeuroRx. 2004;1(4):382-93.

4. Laguna Goya R, Tyers P, Barker RA. The search for a curative cell therapy in Parkinson's disease. J Neurol Sci. 2008;265(1-2):32-42.

5. Wang Y, Chen S, Yang D, Le WD. Stem cell transplantation: a promising therapy for Parkinson's disease. J Neuroimmune Pharmacol. 2007:2(3):243-50.

6. Martin GR. Isolation of a pluripotent cell line from early mouse embryos cultured in medium conditioned by teratocarcinoma stem cells. Proc Natl Acad Sci U S A. 1981;78(12):7634-8.

7. Reubinoff BE, Pera MF, Fong CY, Trounson A, Bongso A. Embryonic stem cell lines from human blastocysts: somatic differentiation in vitro. Nat Biotechnol. 2000;18(4):399-404.

8. Roybon L, Christophersen NS, Brundin P, Li JY. Stem cell therapy for Parkinson's disease: where do we stand? Cell Tissue Res. 2004;318(1):261-73.

9. Evans MJ, Kaufman MH. Establishment in culture of pluripotential cells from mouse embryos. Nature. 1981;292(5819):154-6.

10. Cho MS, Lee YE, Kim JY, Chung S, Cho YH, Kim DS, et al. Highly efficient and large-scale generation of functional dopamine neurons from human embryonic stem cells. Proc Natl Acad Sci U S A. 2008;105(9):3392-7.

11. Kim JH, Auerbach JM, Rodriguez-Gomez JA, Velasco I, Gavin D, Lumelsky N, et al. Dopamine neurons derived from embryonic stem cells function in an animal model of Parkinson's disease. Nature. 2002;418(6893):50-6.

12. Roy NS, Cleren C, Singh SK, Yang L, Beal MF, Goldman SA. Functional engraftment of human ES cell-derived dopaminergic neurons enriched by coculture with telomerase-immortalized midbrain astrocytes. Nat Med. 2006;12(11):1259-68.

13. Brederlau A, Correia AS, Anisimov SV, Elmi M, Paul G, Roybon L, et al. Transplantation of human embryonic stem cell-derived cells to a rat model of Parkinson's disease: effect of in vitro differentiation on graft survival and teratoma formation. Stem Cells. 2006;24(6):1433-40.

14. Kawasaki H, Mizuseki K, Nishikawa S, Kaneko S, Kuwana Y, Nakanishi S, et al. Induction of midbrain dopaminergic neurons from ES cells by stromal cell-derived inducing activity. Neuron. 2000;28(1):31-40.

15. Yue F, Cui L, Johkura K, Ogiwara N, Sasaki K. Induction of midbrain dopaminergic neurons from primate embryonic stem cells by coculture with sertoli cells. Stem Cells. 2006;24(7):1695706.

16. Lee SH, Lumelsky N, Studer L, Auerbach JM, McKay RD. Efficient generation of midbrain and hindbrain neurons from mouse embryonic stem cells. Nat Biotechnol. 2000;18(6):675-9.

17. Takagi Y, Takahashi J, Saiki H, Morizane A, Hayashi T, Kishi Y, et al. Dopaminergic neurons generated from monkey embryonic stem cells function in a Parkinson primate model. J Clin Invest. 2005;115(1):102-9.

18. Morizane A, Takahashi J, Takagi Y, Sasai Y, Hashimoto N. Optimal conditions for in vivo induction of dopaminergic neurons from embryonic stem cells through stromal cell-derived inducing activity. J Neurosci Res. 2002;69(6):934-9.

19. Kawasaki H, Suemori H, Mizuseki K, Watanabe K, Urano F, Ichinose $\mathrm{H}$, et al. Generation of dopaminergic neurons and pigmented epithelia from primate ES cells by stromal cell-derived inducing activity. Proc Natl Acad Sci U S A. 2002;99(3):1580-5.

20. Iacovitti L, Donaldson AE, Marshall CE, Suon S, Yang M. A protocol for the differentiation of human embryonic stem cells into dopaminergic neurons using only chemically defined human additives: Studies in vitro and in vivo. Brain Res. 2007;1127(1):19-25.

21. Thomson JA, Itskovitz-Eldor J, Shapiro SS, Waknitz MA, Swiergiel JJ, Marshall VS, et al. Embryonic stem cell lines derived from human blastocysts. Science. 1998;282(5391):1145-7.

22. Okabe S, Forsberg-Nilsson K, Spiro AC, Segal M, McKay RD. Development of neuronal precursor cells and functional postmitotic neurons from embryonic stem cells in vitro. Mech Dev. 1996;59(1):89-102.

23. Reubinoff BE, Itsykson P, Turetsky T, Pera MF, Reinhartz E, Itzik A et al. Neural progenitors from human embryonic stem cells. Nat Biotechnol. 2001:19(12):1134-40.

24. Schulz TC, Palmarini GM, Noggle SA, Weiler DA, Mitalipova MM, Condie BG. Directed neuronal differentiation of human embryonic stem cells. BMC Neurosci. 2003;4:27.

25. Daadi MM, Grueter BA, Malenka RC, Redmond DE, Jr, Steinberg GK. Dopaminergic neurons from midbrain-specified human embryonic stem cell-derived neural stem cells engrafted in a monkey model of Parkinson's disease. PLoS One. 2012;7(7):ee41120 .

26. Bjorklund LM, Sanchez-Pernaute R, Chung S, Andersson T, Chen IY, McNaught KS, et al. Embryonic stem cells develop into functional dopaminergic neurons after transplantation in a Parkinson rat model. Proc Natl Acad Sci U S A. 2002;99(4):2344-9.

27. Shingo T. [Cell therapy in Parkinson's disease]. Rinsho Shinkeigaku. 2004;44(11):951-3.

28. Li M, Pevny L, Lovell-Badge R, Smith A. Generation of purified neural precursors from embryonic stem cells by lineage selection. Curr Biol.1998;8(17):971-4.

29. Conti L, Pollard SM, Gorba T, Reitano E, Toselli M, Biella G, et al. 
Niche-independent symmetrical self-renewal of a mammalian tissue stem cell. PLoS Biol. 2005;3(9):ee283

30. Hedlund E, Pruszak J, Lardaro T, Ludwig W, Vinuela A, Kim KS, et al. Embryonic stem cell-derived Pitx3-enhanced green fluorescent protein midbrain dopamine neurons survive enrichment by fluorescence-activated cell sorting and function in an animal model of Parkinson's disease. Stem Cells. 2008;26(6):1526-36.

31. Maitra A, Arking DE, Shivapurkar N, Ikeda M, Stastny V, Kassauei $\mathrm{K}$, et al. Genomic alterations in cultured human embryonic stem cells. Nat Genet. 2005:37(10):1099-103.

32. Roth G, Dicke U. Evolution of the brain and intelligence. Trends Cogn Sci. 2005;9(5):250-7.

33. Palmer TD, Schwartz PH, Taupin P, Kaspar B, Stein SA, Gage FH. Cell culture. Progenitor cells from human brain after death. $\mathrm{Na}$ ture. 2001; $411(6833): 42-3$.

34. Studer L, Tabar V, McKay RD. Transplantation of expanded mesencephalic precursors leads to recovery in parkinsonian rats. Nat Neurosci. 1998;1(4):290-5.

35. Yan J, Studer L, McKay RD. Ascorbic acid increases the yield of dopaminergic neurons derived from basic fibroblast growth factor expanded mesencephalic precursors. J Neurochem. 2001;76(1):307-11.

36. Mimeault M, Batra SK. Concise review: recent advances on the significance of stem cells in tissue regeneration and cancer therapies. Stem Cells. 2006;24(11):2319-45.

37. Harrower TP, Tyers P, Hooks Y, Barker RA. Long-term survival and integration of porcine expanded neural precursor cell grafts in a rat model of Parkinson's disease. Exp Neurol. 2006;197(1):56-69.

38. Timmer M, Grosskreutz J, Schlesinger F, Krampfl K, Wesemann $\mathrm{M}$, Just L, et al. Dopaminergic properties and function after grafting of attached neural precursor cultures. Neurobiol Dis. 2006;21(3):587-606.

39. Studer L, Csete M, Lee SH, Kabbani N, Walikonis J, Wold B, et al. Enhanced proliferation, survival, and dopaminergic differentiation of CNS precursors in lowered oxygen. J Neurosci. 2000;20(19):7377-83.

40. Potter ED, Ling ZD, Carvey PM. Cytokine-induced conversion of mesencephalic-derived progenitor cells into dopamine neurons. Cell Tissue Res. 1999;296(2):235-46.

41. Storch A, Paul G, Csete M, Boehm BO, Carvey PM, Kupsch A, et al. Long-term proliferation and dopaminergic differentiation of human mesencephalic neural precursor cells. Exp Neurol. 2001;170(2):317-25.

42. Perlow MJ, Freed WJ, Hoffer BJ, Seiger A, Olson L, Wyatt RJ. Brain grafts reduce motor abnormalities produced by destruction of nigrostriatal dopamine system. Science. 1979;204(4393):643-7.

43. Bjorklund A, Dunnett SB, Stenevi U, Lewis ME, Iversen SD. Reinnervation of the denervated striatum by substantia nigra transplants: functional consequences as revealed by pharmacological and sensorimotor testing. Brain Res. 1980;199(2):307-33.

44. Bjorklund A, Schmidt RH, Stenevi U. Functional reinnervation of the neostriatum in the adult rat by use of intraparenchymal grafting of dissociated cell suspensions from the substantia nigra. Cell Tissue Res. 1980;212(1):39-45.

45. Svendsen CN, Caldwell MA, Shen J, ter Borg MG, Rosser AE, Tyers $P$, et al. Long-term survival of human central nervous system progenitor cells transplanted into a rat model of Parkinson's disease. Exp Neurol. 1997;148(1):135-46.

46. Redmond DE, Jr, Bjugstad KB, Teng YD, Ourednik V, Ourednik J, Wakeman DR, et al. Behavioral improvement in a primate Parkinson's model is associated with multiple homeostatic effects of human neural stem cells. Proc Natl Acad Sci U S A. 2007;104(29):12175-80.

47. Politis M. Optimizing functional imaging protocols for assessing the outcome of fetal cell transplantation in Parkinson's disease. BMC Med. 2011;9:50.

48. Wictorin K, Brundin P, Sauer H, Lindvall O, Bjorklund A. Long distance directed axonal growth from human dopaminergic mesencephalic neuroblasts implanted along the nigrostriatal pathway in 6-hydroxydopamine lesioned adult rats. J Comp Neurol. 1992;323(4):475-94.

49. Lindvall O, Sawle G, Widner H, Rothwell JC, Bjorklund A, Brooks D, et al. Evidence for long-term survival and function of dopaminergic grafts in progressive Parkinson's disease. Ann Neurol. 1994;35(2):172-80

50. Hagell P, Piccini P, Bjorklund A, Brundin P, Rehncrona S, Widner $\mathrm{H}$, et al. Dyskinesias following neural transplantation in Parkinson's disease. Nat Neurosci. 2002;5(7):627-8.

51. Lindvall O. Neural transplantation: a hope for patients with Parkinson's disease. Neuroreport.1997;8(14):iii-X.

52. Kordower JH, Freeman TB, Snow BJ, Vingerhoets FJ, Mufson EJ, Sanberg PR, et al. Neuropathological evidence of graft survival and striatal reinnervation after the transplantation of fetal mesencephalic tissue in a patient with Parkinson's disease. $N$ Engl J Med.1995;332(17):1118-24.

53. Piccini P, Brooks DJ, Bjorklund A, Gunn RN, Grasby PM, Rimoldi $\mathrm{O}$, et al. Dopamine release from nigral transplants visualized in vivo in a Parkinson's patient. Nat Neurosci. 1999;2(12):1137-40.

54. Lindvall O. Stem cells for cell therapy in Parkinson's disease. Pharmacol Res. 2003;47(4):279-87.

55. Altman J, Das GD. Autoradiographic and histological evidence of postnatal hippocampal neurogenesis in rats. J Comp Neurol. 1965;124(3):319-35.

56. Reynolds BA, Weiss S. Generation of neurons and astrocytes from isolated cells of the adult mammalian central nervous system. Science. 1992;255(5052):1707-10.

57. Daadi MM, Weiss S. Generation of tyrosine hydroxylase-producing neurons from precursors of the embryonic and adult forebrain. J Neurosci. 1999;19(11):4484-97.

58. Lie DC, Dziewczapolski G, Willhoite AR, Kaspar BK, Shults CW, Gage FH. The adult substantia nigra contains progenitor cells with neurogenic potential. J Neurosci. 2002;22(15):6639-49.

59. Dezawa M, Kanno H, Hoshino M, Cho H, Matsumoto N, Itokazu $\mathrm{Y}$, et al. Specific induction of neuronal cells from bone marrow stromal cells and application for autologous transplantation. $J$ Clin Invest. 2004;113(12):1701-10.

60. Li Y, Chen J, Wang L, Zhang L, Lu M, Chopp M. Intracerebral transplantation of bone marrow stromal cells in a 1-methyl-4-phenyl1,2,3,6-tetrahydropyridine mouse model of Parkinson's disease. Neurosci Lett. 2001;316(2):67-70.

61. Jiang Y, Jahagirdar BN, Reinhardt RL, Schwartz RE, Keene CD, Ortiz-Gonzalez XR, et al. Pluripotency of mesenchymal stem cells derived from adult marrow. Nature. 2002;418(6893):41-9.

62. Lu L, Zhao C, Liu Y, Sun X, Duan C, Ji M, et al. Therapeutic benefit of TH-engineered mesenchymal stem cells for Parkinson's disease. Brain Res Brain Res Protoc. 2005;15(1):46-51.

63. Hermann A, Maisel M, Storch A. Epigenetic conversion of human adult bone mesodermal stromal cells into neuroectodermal cell types for replacement therapy of neurodegenerative disorders. Expert Opin Biol Ther. 2006;6(7):653-70.

64. Venkataramana NK, Kumar SK, Balaraju S, Radhakrishnan RC, Bansal A, Dixit A, et al. Open-labeled study of unilateral autologous bone-marrow-derived mesenchymal stem cell transplantation in Parkinson's disease. Transl Res. 2010;155(2):62-70.

65. McGuckin CP, Forraz N, Allouard Q, Pettengell R. Umbilical cord blood stem cells can expand hematopoietic and neuroglial progenitors in vitro. Exp Cell Res. 2004;295(2):350-9.

66. Weiss ML, Medicetty S, Bledsoe AR, Rachakatla RS, Choi M, Merchav $\mathrm{S}$, et al. Human umbilical cord matrix stem cells: preliminary characterization and effect of transplantation in a rodent model of Parkinson's disease. Stem Cells. 2006;24(3):781-92.

67. Takahashi K, Yamanaka S. Induction of pluripotent stem cells from mouse embryonic and adult fibroblast cultures by defined factors. Cell. 2006;126(4):663-76.

68. Tabar V, Tomishima M, Panagiotakos G, Wakayama S, Menon J, Chan B, et al. Therapeutic cloning in individual parkinsonian mice. Nat Med. 2008;14(4):379-81.

69. Wernig M, Zhao JP, Pruszak J, Hedlund E, Fu D, Soldner F, et al. 
Neurons derived from reprogrammed fibroblasts functionally integrate into the fetal brain and improve symptoms of rats with Parkinson's disease. Proc Natl Acad Sci U S A. 2008;105(15):5856-61.

70. Hargus G, Cooper O, Deleidi M, Levy A, Lee K, Marlow E, et al. Differentiated Parkinson patient-derived induced pluripotent stem cells grow in the adult rodent brain and reduce motor asymmetry in Parkinsonian rats. Proc Natl Acad Sci U S A. 2010;107(36):15921-6.

71. Swistowski A, Peng J, Liu Q, Mali P, Rao MS, Cheng L, et al. Efficient generation of functional dopaminergic neurons from human induced pluripotent stem cells under defined conditions. Stem Cells. 2010;28(10):1893-904.

72. Nakao N, Shintani-Mizushima A, Kakishita K, Itakura T. The ability of grafted human sympathetic neurons to synthesize and store dopamine: a potential mechanism for the clinical effect of sympathetic neuron autografts in patients with Parkinson's disease. Exp Neurol. 2004;188(1):65-73.

73. Madrazo I, Drucker-Colin R, Diaz V, Martinez-Mata J, Torres C,
Becerril JJ. Open microsurgical autograft of adrenal medulla to the right caudate nucleus in two patients with intractable Parkinson's disease. N Engl J Med. 1987;316(14):831-4.

74. Goetz CG, Stebbins GT, 3rd, Klawans HL, Koller WC, Grossman RG Bakay RA, et al. United Parkinson Foundation Neurotransplantation Registry on adrenal medullary transplants: presurgical, and 1- and 2-year follow-up. Neurology. 1991;41(11):1719-22.

75. McGregor KH, Gil J, Lahiri S. A morphometric study of the carotid body in chronically hypoxic rats. J Appl Physiol Respir Environ Exerc Physiol. 1984;57(5):1430-8.

76. Espejo EF, Montoro RJ, Armengol JA, Lopez-Barneo J. Cellular and functional recovery of Parkinsonian rats after intrastriatal transplantation of carotid body cell aggregates. Neuron. 1998;20(2):197-206.

77. Luquin MR, Montoro RJ, Guillen J, Saldise L, Insausti R, Del Rio J, et al. Recovery of chronic parkinsonian monkeys by autotransplants of carotid body cell aggregates into putamen. Neuron. 1999;22(4):743-50. 